\title{
Dynamic behaviors of a stage structure amensalism system with a cover for the first species
}

\section{Chaoquan Lei ${ }^{1^{*}}$}

\section{"Correspondence:}

leichaoquan2017@163.com

'Department of Mathematics,

Ningde Normal University, Ningde, China

\begin{abstract}
In this paper, we propose and study a two-species stage structured amensalism model with a cover for the first species. By developing a new analysis technique or, more precisely, by combining the differential inequality theory and the Lyapunov function method, we obtain sufficient conditions ensuring the global attractivity of positive and boundary equilibria, respectively. Our study shows that the final density of the first species is an increasing function of the partial cover, and if the stage structured species is globally asymptotically stable, then there exists a threshold such that if the cover is greater than this threshold, the species can still exist in the long run, whereas if the cover is too small, then the first species is driven to extinction.
\end{abstract}

MSC: 34C25; 92D25; 34D20; 34D40

Keywords: Stage structure; Amensalism; Lyapunov function; Differential inequality; Global stability

\section{Introduction}

The aim of this paper is to investigate the dynamic behavior of the following stage structure amensalism system with a cover for the first species:

$$
\begin{aligned}
& \frac{d x_{1}}{d t}=\alpha x_{2}-\beta x_{1}-\delta_{1} x_{1}-d_{1}(1-k) x_{1} y, \\
& \frac{d x_{2}}{d t}=\beta x_{1}-\delta_{2} x_{2}-\gamma x_{2}^{2}-d_{2}(1-k) x_{2} y, \\
& \frac{d y}{d t}=y\left(b_{2}-a_{2} y\right),
\end{aligned}
$$

where $\alpha, \beta, \delta_{1}, \delta_{2}, d_{1}, d_{2}, k, b_{2}, a_{2}$, and $\gamma$ are positive constants, $x_{1}(t)$ and $x_{2}(t)$ are the densities of the immature and mature first species at time $t, y$ is the density of the second species at time $t$, and $k \in(0,1)$ is a cover provided for the first species. The following assumptions are made in model (1.1):

1. The first species has two-stage structure, immature and mature. Its dynamic behavior is described by the equation system

$$
\frac{d x_{1}}{d t}=\alpha x_{2}-\beta x_{1}-\delta_{1} x_{1},
$$

(c) The Author(s) 2018. This article is distributed under the terms of the Creative Commons Attribution 4.0 International License (http://creativecommons.org/licenses/by/4.0/), which permits unrestricted use, distribution, and reproduction in any medium, provided you give appropriate credit to the original author(s) and the source, provide a link to the Creative Commons license, and indicate if changes were made. 


$$
\frac{d x_{2}}{d t}=\beta x_{1}-\delta_{2} x_{2}-\gamma x_{2}^{2}
$$

We refer to Khajanchi and Banerjee [1] for more background of this equation system.

2. There is a partial cover (represented by $k$ ) for the first species to protect it from the second species.

3. Both relationships between the immature species and the second species and between the mature species and the second species are bilinear: $\left(d_{1}(1-k) x_{1} y\right.$ and $\left.d_{2}(1-k) x_{2} y\right)$.

4. The second species satisfies the logistic model.

During the last decades, many scholars investigated the dynamic behavior of the commensalism or amensalism model [2-19]. Such topics as the local stability of the equilibrium $[2-4,7,8,10-16,18,19]$, the existence of the positive periodic solution $[5,17]$ the existence and stability of the almost periodic solution [6], extinction of the species [8, 11, 14], and the influence of the cover $[14,16,18]$ have been studied, and many excellent results are obtained. Recently, Xiong, Wang, and Zhang [13] proposed the following amensalism model:

$$
\begin{aligned}
& \frac{d N_{1}}{d t}=r_{1} N_{1}\left(1-\frac{N_{1}}{P_{1}}-u \frac{N_{2}}{P_{1}}\right), \\
& \frac{d N_{2}}{d t}=r_{2} N_{2}\left(1-\frac{N_{2}}{P_{2}}\right) .
\end{aligned}
$$

The authors investigated the local stability property of the equilibria of the system.

Zhu and Chen [10] studied the qualitative property of the following two-species amensalism model:

$$
\begin{aligned}
& \frac{d x}{d t}=x\left(r_{1}-a_{11} x-a_{12} y\right), \\
& \frac{d y}{d t}=y\left(r_{2}-a_{22} y\right) .
\end{aligned}
$$

They showed by a vector field that system (1.3) may have a positive equilibrium, and it is globally stable, or that the system has no positive equilibrium, and one of the boundary equilibria is globally stable.

Stimulated by the work [13], Chen [15] proposed the following nonselective harvesting Lotka-Volterra amensalism model incorporating partial closure for the populations:

$$
\begin{aligned}
& \frac{d N_{1}}{d t}=r_{1} N_{1}\left(1-\frac{N_{1}}{P_{1}}-u \frac{N_{2}}{P_{1}}\right)-q_{1} E m N_{1} \\
& \frac{d N_{2}}{d t}=r_{2} N_{2}\left(1-\frac{N_{2}}{P_{2}}\right)-q_{2} E m N_{2} .
\end{aligned}
$$

Chen showed that after introducing the harvesting term, the dynamic behavior of system (1.4) becomes complicated, the system maybe extinction, partial survival, or two species can coexist in a stable state.

Some scholars argued that the functional response between the species is the essential factor to influence the dynamic behavior of the system. For example, $\mathrm{Wu}$ [19] proposed a 
two-species amensalism model with nonmonotonic functional response, which takes the form

$$
\begin{aligned}
& \frac{d x_{1}}{d t}=x_{1}\left(a_{1}-b_{1} x_{1}-\frac{c_{1} x_{2}}{d_{1}+x_{2}^{2}}\right), \\
& \frac{d x_{2}}{d t}=x_{2}\left(a_{2}-b_{2} x_{2}\right) .
\end{aligned}
$$

They showed that the dynamic behavior of system (1.5) is similar to that of system (1.3).

It is well known that refuge plays an important role on the dynamic behavior of the predator-prey system (see [20-23]). Stimulated by the notion of the refuge, Xie, Chen, and He [18] studied the following two species amensalism model with a partial cover for the first species to protect it from the second species:

$$
\begin{aligned}
& \frac{d x}{d t}=a_{1} x(t)-b_{1} x^{2}(t)-a_{12}(1-k) x(t) y(t), \\
& \frac{d y}{d t}=a_{2} y(t)-b_{2} y^{2}(t) .
\end{aligned}
$$

Their study indicates that the conditions that ensure the local stability of the boundary equilibrium are sufficient to ensure its global stability, and once a positive equilibrium exists, it is globally stable. Their results were then generalized by Wu, Zhao, and Lin [14] to a two-species amensalism model with Holling II functional response and a cover for the first species.

On the other hand, many scholars investigated the dynamic behavior of the stage structured species; see [1, 24-36] and the references therein. Many scholars [24-34] argued that a suitable stage-structured model should incorporate the time delay, which reflects the period of immature species to grow up to mature species. For example, Lin, Xie, and Chen [32] proposed the following stage-structured predator-prey model (stage structure for both predator and prey, respectively) with modified Leslie-Gower and Holling-type II schemes:

$$
\begin{aligned}
& x_{1}^{\prime}(t)=r_{1} x_{2}(t)-d_{11} x_{1}(t)-r_{1} e^{-d_{11} \tau_{1}} x_{2}\left(t-\tau_{1}\right), \\
& x_{2}^{\prime}(t)=r_{1} e^{-d_{11} \tau_{1}} x_{2}\left(t-\tau_{1}\right)-d_{12} x_{2}(t)-b x_{2}^{2}(t)-\frac{a_{1} y_{2}(t) x_{2}(t)}{x_{2}(t)+k_{1}}, \\
& y_{1}^{\prime}(t)=r_{2} y_{2}(t)-d_{22} y_{1}(t)-r_{2} e^{-d_{22} \tau_{2}} y_{2}\left(t-\tau_{2}\right), \\
& y_{2}^{\prime}(t)=r_{2} e^{-d_{22} \tau_{2}} y_{2}\left(t-\tau_{2}\right)-d_{21} y_{2}(t)-\frac{a_{2} y_{2}^{2}(t)}{x_{2}(t)+k_{2}} .
\end{aligned}
$$

They showed that for a stage-structured predator-prey community, both stage structure and death rate of the mature species are the important factors that lead to the permanence or extinction of the system.

Many scholars $[1,35,36]$ also proposed and studied the stage-structured ecosystem without time delay, that is, they assumed that there are proportional numbers of immature species that become mature species at time $t$. Recently, Khajanchi and Banerjee [1] proposed the following stage structure predator-prey model with ratio dependent functional 
response:

$$
\begin{aligned}
& \frac{d x_{1}}{d t}=\alpha x_{2}(t)-\beta x_{1}(t)-\delta_{1} x_{1}(t), \\
& \frac{d x_{2}}{d t}=\beta x_{1}(t)-\delta_{2} x_{2}(t)-\gamma x_{2}^{2}(t)-\frac{\eta(1-\theta) x_{2}(t) y(t)}{g(1-\theta) x_{2}(t)+h y(t)}, \\
& \frac{d y}{d t}=\frac{u \eta(1-\theta) x_{2}(t) y(t)}{g(1-\theta) x_{2}(t)+h y(t)}-\delta_{3} y(t) .
\end{aligned}
$$

The authors investigated the stability property of the positive equilibrium and boundary equilibrium.

Stimulated by the works of Chen [15] and Khajanchi and Banerjee [1], we [36] proposed the following single-species stage structure system incorporating partial closure for the populations and nonselective harvesting:

$$
\begin{aligned}
& \frac{d x_{1}}{d t}=\alpha x_{2}-\beta x_{1}-\delta_{1} x_{1}-q_{1} E m x_{1}, \\
& \frac{d x_{2}}{d t}=\beta x_{1}-\delta_{2} x_{2}-\gamma x_{2}^{2}-q_{2} E m x_{2} .
\end{aligned}
$$

We showed that the birth rate of the immature species and the fraction of the stocks for the harvesting play a crucial role on the dynamic behavior of the system.

It brings to our attention that, to this day, still no scholars propose and study the dynamic behaviors of the amensalism model with stage structure. This motivated us to propose system (1.1). We mention here that at first sight, system (1.1) is very simple, However, the third equation is independent of $x_{1}$ and $x_{2}$, and hence it is impossible to investigate the stability property of the system by constructing a suitable Lyapunov function. Also, since this is a three-dimensional system, we cannot investigate the stability property of the system by using the Dulac criterion.

The paper is arranged as follows. We investigate the existence and locally stability property of the equilibria of system (1.1) in Sect. 2. In Sect. 3, by applying the differential inequality theory and constructing some suitable Lyapunov function we are able to investigate the global attractivity of the positive and boundary equilibria. We then discuss the influence of partial cover to the final density of the first species in Sect. 4, and in Sect. 5, we present an example together with its numerical simulations to show the feasibility of the main results. We end this paper by a brief discussion.

\section{Local stability of the equilibria}

Before we study the local stability property of the equilibrium points of system (1.1), we introduce the stability of equilibrium of the following single-species stage-structured system:

$$
\begin{aligned}
& \frac{d x_{1}}{d t}=\alpha x_{2}-\beta x_{1}-\delta_{1} x_{1}, \\
& \frac{d x_{2}}{d t}=\beta x_{1}-\delta_{2} x_{2}-\gamma x_{2}^{2},
\end{aligned}
$$

where $\alpha, \beta, \delta_{1}, \delta_{2}$, and $\gamma$ are positive constants. The following lemma is Theorems 4.1 and 4.2 of [36]. 


\section{Lemma 2.1 If}

$$
\alpha \beta<\delta_{2}\left(\beta+\delta_{1}\right)
$$

then the boundary equilibrium $O(0,0)$ of system $(2.1)$ is globally stable. If

$$
\alpha \beta>\delta_{2}\left(\beta+\delta_{1}\right),
$$

then the positive equilibrium $B\left(x_{1}^{*}, x_{2}^{*}\right)$ of system (2.1) is globally stable, where

$$
x_{1}^{*}=\frac{\alpha x_{2}^{*}}{\beta+\delta_{1}}, \quad x_{2}^{*}=\frac{\alpha \beta-\delta_{2}\left(\beta+\delta_{1}\right)}{\gamma\left(\beta+\delta_{1}\right)} .
$$

Now we are in position to investigate the local stability property of system (1.1).

The equilibria of system (1.1) are determined by the system

$$
\begin{aligned}
& \alpha x_{2}-\beta x_{1}-\delta_{1} x_{1}-d_{1}(1-k) x_{1} y=0, \\
& \beta x_{1}-\delta_{2} x_{2}-\gamma x_{2}^{2}-d_{2}(1-k) x_{2} y=0, \\
& y\left(b_{2}-a_{2} y\right)=0 .
\end{aligned}
$$

The system always admits two boundary equilibria, $A_{1}(0,0,0)$ and $A_{2}\left(0,0, \frac{b_{2}}{a_{2}}\right)$. If

$$
\alpha \beta>\delta_{2}\left(\beta+\delta_{1}\right)
$$

then the system admits boundary equilibrium $A_{3}\left(x_{1}^{*}, x_{2}^{*}, 0\right)$, where

$$
x_{1}^{*}=\frac{\alpha x_{2}^{*}}{\beta+\delta_{1}}, \quad x_{2}^{*}=\frac{\alpha \beta-\delta_{2}\left(\beta+\delta_{1}\right)}{\gamma\left(\beta+\delta_{1}\right)} .
$$

If

$$
\alpha \beta-\left(\delta_{2}+\frac{d_{2}(1-k) b_{2}}{a_{2}}\right)\left(\beta+\delta_{1}+\frac{d_{1}(1-k) b_{2}}{a_{2}}\right)>0,
$$

then system (1.1) admits a unique positive equilibrium $A_{4}\left(x_{1}^{* *}, x_{2}^{* *}, y^{* *}\right)$, where

$$
\begin{aligned}
& x_{1}^{* *}=\frac{\alpha x_{2}^{* *}}{\beta+\delta_{1}+\frac{d_{1}(1-k) b_{2}}{a_{2}}}, \\
& x_{2}^{* *}=\frac{\alpha \beta-\left(\delta_{2}+\frac{d_{2}(1-k) b_{2}}{a_{2}}\right)\left(\beta+\delta_{1}+\frac{d_{1}(1-k) b_{2}}{a_{2}}\right)}{\left(\beta+\delta_{1}+\frac{d_{1}(1-k) b_{2}}{a_{2}}\right) \gamma}, \\
& y^{* *}=\frac{b_{2}}{a_{2}} .
\end{aligned}
$$

Obviously, $x_{1}^{* *}, x_{2}^{* *}$, and $y^{* *}$ satisfy the equations

$$
\begin{aligned}
& \alpha x_{2}^{* *}-\beta x_{1}^{* *}-\delta_{1} x_{1}^{* *}-d_{1}(1-k) x_{1}^{* *} y^{* *}=0, \\
& \beta x_{1}^{* *}-\delta_{2} x_{2}^{* *}-\gamma\left(x_{2}^{* *}\right)^{2}-d_{2}(1-k) x_{2}^{* *} y^{* *}=0, \\
& b_{2}-a_{2} y^{* *}=0
\end{aligned}
$$


We will now investigate the local stability of the above equilibria.

The variational matrix of system (1.1) is

$$
J\left(x_{1}, x_{2}, y\right)=\left(\begin{array}{ccc}
\Delta_{1} & \alpha & -d_{1}(1-k) x_{1} \\
\beta & \Delta_{2} & -d_{2}(1-k) x_{2} \\
0 & 0 & -2 a_{2} y+b_{2}
\end{array}\right),
$$

where

$$
\begin{aligned}
& \Delta_{1}=-\beta-\delta_{1}-d_{1}(1-k) y, \\
& \Delta_{2}=-\delta_{2}-2 \gamma x_{2}-d_{2}(1-k) y .
\end{aligned}
$$

Theorem 2.1 $A_{1}(0,0,0)$ is unstable.

Proof From (2.10) we can see that the Jacobian matrix of the system about the equilibrium point $A_{1}(0,0,0)$ is given by

$$
\left(\begin{array}{ccc}
-\beta-\delta_{1} & \alpha & 0 \\
\beta & -\delta_{2} & 0 \\
0 & 0 & b_{2}
\end{array}\right)
$$

We can easily see that it has one positive characteristic root $\lambda_{1}=b_{2}$, and, consequently, $A_{1}(0,0,0)$ is unstable. This ends the proof of Theorem 2.1.

\section{Theorem 2.2 If}

$$
\left(\delta_{2}+\frac{d_{2}(1-k) b_{2}}{a_{2}}\right)\left(\beta+\delta_{1}+\frac{d_{1}(1-k) b_{2}}{a_{2}}\right)-\alpha \beta>0,
$$

then $A_{2}\left(0,0, \frac{b_{2}}{a_{2}}\right)$ is locally asymptotically stable. If

$$
\left(\delta_{2}+\frac{d_{2}(1-k) b_{2}}{a_{2}}\right)\left(\beta+\delta_{1}+\frac{d_{1}(1-k) b_{2}}{a_{2}}\right)-\alpha \beta<0,
$$

then $A_{2}\left(0,0, \frac{b_{2}}{a_{2}}\right)$ is unstable.

Proof From (2.10) we can see that the Jacobian matrix of the system about the equilibrium point $A_{2}\left(0,0, \frac{b_{2}}{a_{2}}\right)$ is given by

$$
\left(\begin{array}{ccc}
-\beta-\delta_{1}-\frac{d_{1}(1-k) b_{2}}{a_{2}} & \alpha & 0 \\
\beta & -\delta_{2}-\frac{d_{2}(1-k) b_{2}}{a_{2}} & 0 \\
0 & 0 & -b_{2}
\end{array}\right)
$$

The characteristic equation of this matrix is

$$
\left(\lambda+b_{2}\right)\left[\lambda^{2}+K_{1} \lambda+K_{2}\right]=0
$$


where

$$
\begin{aligned}
& K_{1}=\delta_{1}+\delta_{2}+\beta+\frac{d_{1}(1-k) b_{2}}{a_{2}}+\frac{d_{2}(1-k) b_{2}}{a_{2}}, \\
& K_{2}=\left(\beta+\delta_{1}+\frac{d_{1}(1-k) b_{2}}{a_{2}}\right)\left(\delta_{2}+\frac{d_{2}(1-k) b_{2}}{a_{2}}\right)-\alpha \beta .
\end{aligned}
$$

Hence it has one negative characteristic root $\lambda_{1}=-b_{2}<0$; the other two characteristic roots are determined by the equation

$$
\lambda^{2}+K_{1} \lambda+K_{2}=0
$$

Note that the two characteristic roots of equation (2.16) satisfy

$$
\lambda_{2}+\lambda_{3}=-K_{1}, \quad \lambda_{2} \lambda_{3}=K_{2} .
$$

Under assumption (2.13), $\lambda_{2} \lambda_{3}<0$, hence at least one characteristic root is positive, and, consequently, $A_{2}\left(0,0, \frac{b_{2}}{a_{2}}\right)$ is unstable. Under assumption (2.12), $\lambda_{2}<0$ and $\lambda_{3}<0$. Thus three characteristic roots of matrix (2.14) are all negative, and hence $A_{1}\left(0,0, \frac{b_{2}}{a_{2}}\right)$ is locally asymptotically stable. This ends the proof of Theorem 2.2.

Theorem $2.3 A_{3}\left(x_{1}^{*}, x_{2}^{*}, 0\right)$ is unstable.

Proof From (2.10) we can see that the Jacobian matrix of the system about the equilibrium point $A_{3}\left(x_{1}^{*}, x_{2}^{*}, 0\right)$ is given by

$$
\left(\begin{array}{ccc}
-\beta-\delta_{1} & \alpha & -d_{1}(1-k) x_{1}^{*} \\
\beta & -\delta_{2}-2 \gamma x_{2}^{*} & -d_{2}(1-k) x_{2}^{*} \\
0 & 0 & b_{2}
\end{array}\right) .
$$

From (2.18) we can easily see that the matrix has one positive characteristic root $\lambda_{1}=b_{2}$, and, consequently, $A_{3}\left(x_{1}^{*}, x_{2}^{*}, 0\right)$ is unstable. This ends the proof of Theorem 2.3.

\section{Theorem 2.4 If}

$$
\left(\delta_{2}+\frac{d_{2}(1-k) b_{2}}{a_{2}}\right)\left(\beta+\delta_{1}+\frac{d_{1}(1-k) b_{2}}{a_{2}}\right)-\alpha \beta<0,
$$

then $A_{4}\left(x_{1}^{* *}, x_{2}^{* *}, y^{* *}\right)$ is locally asymptotically stable.

Proof From (2.10) we can see that the Jacobian matrix of the system about the equilibrium point $A_{4}\left(x_{1}^{* *}, x_{2}^{* *}, y^{* *}\right)$ is given by

$$
\left(\begin{array}{ccc}
\Gamma_{1} & \alpha & -d_{1}(1-k) x_{1}^{* *} \\
\beta & \Gamma_{2} & -d_{2}(1-k) x_{2}^{* *} \\
0 & 0 & -2 a_{2} y^{* *}+b_{2}
\end{array}\right)
$$

where

$$
\Gamma_{1}=-\beta-\delta_{1}-d_{1}(1-k) y^{* *},
$$




$$
\Gamma_{2}=-\delta_{2}-2 \gamma x_{2}^{* *}-d_{2}(1-k) y^{* *} .
$$

Noting that

$$
-2 a_{2} y^{* *}+b_{2}=-2 a_{2} \frac{b_{2}}{a_{2}}+b_{2}=-b_{2},
$$

from the second equation of (2.9) we have

$$
\begin{aligned}
-\delta_{2} & -2 \gamma x_{2}^{* *}-d_{2}(1-k) y^{* *} \\
& =-\frac{\beta x_{1}^{* *}}{x_{2}^{* *}}-\gamma x_{2}^{* *} \\
& =-\frac{\alpha \beta}{\beta+\delta_{1}+\frac{d_{1}(1-k) b_{2}}{a_{2}}}-\gamma x_{2}^{* *} .
\end{aligned}
$$

The characteristic equation of above matrix is

$$
\left(\lambda+b_{2}\right)\left[\lambda^{2}+B_{1} \lambda+B_{2}\right]=0
$$

where

$$
\begin{aligned}
& B_{1}=\beta+\delta_{1}+d_{1}(1-k) y^{* *}+\frac{\alpha}{\beta+\delta_{1}+\frac{d_{1}(1-k) b_{2}}{a_{2}}}+\gamma x_{2}^{* *}, \\
& B_{2}=\left(\beta+\delta_{1}+d_{1}(1-k) y^{* *}\right)\left(\frac{\beta \alpha}{\beta+\delta_{1}+\frac{d_{1}(1-k) b_{2}}{a_{2}}}+\gamma x_{2}^{* *}\right)-\alpha \beta .
\end{aligned}
$$

Hence it has one negative characteristic root $\lambda_{1}=-b_{2}<0$, and the other two characteristic roots are determined by the equation

$$
\lambda^{2}+B_{1} \lambda+B_{2}=0
$$

Note that by the expressions of $x_{2}^{* *}$ and $y^{* *}$ and by condition (2.19) the two characteristic roots of equation (2.22) satisfy

$$
\begin{aligned}
\lambda_{2}+\lambda_{3} & =-B_{1}<0, \\
\lambda_{2} \lambda_{3} & =\left(\beta+\delta_{1}+d_{1}(1-k) y^{* *}\right) L_{1}-\alpha \beta \\
& =\left(\beta+\delta_{1}+d_{1}(1-k) \frac{b_{2}}{a_{2}}\right) L_{1}-\alpha \beta \\
& =\alpha \beta-\left(\delta_{2}+\frac{d_{2}(1-k) b_{2}}{a_{2}}\right)\left(\beta+\delta_{1}+\frac{d_{1}(1-k) b_{2}}{a_{2}}\right)
\end{aligned}
$$

$$
>0 \text {, }
$$

where

$$
L_{1}=\frac{\beta \alpha}{\beta+\delta_{1}+\frac{d_{1}(1-k) b_{2}}{a_{2}}}+\gamma x_{2}^{* *}
$$




$$
=\frac{2 \alpha \beta-\left(\delta_{2}+\frac{d_{2}(1-k) b_{2}}{a_{2}}\right)\left(\beta+\delta_{1}+\frac{d_{1}(1-k) b_{2}}{a_{2}}\right)}{\beta+\delta_{1}+\frac{d_{1}(1-k) b_{2}}{a_{2}}} .
$$

Hence $\lambda_{2}<0$ and $\lambda_{3}<0$, and therefore all of three characteristic roots are negative. Consequently, $A_{4}\left(x_{1}^{* *}, x_{2}^{* *}, y^{* *}\right)$ is locally asymptotically stable. This ends the proof of Theorem 2.4.

\section{Global stability}

As was shown in the previous section, under some suitable conditions, $A_{2}$ and $A_{4}$ can be locally asymptotically stable. In this section, we obtain some sufficient conditions that for the global asymptotical stability of the equilibria $A_{2}$ and $A_{4}$.

\section{Theorem 3.1 If}

$$
\left(\delta_{2}+\frac{d_{2}(1-k) b_{2}}{a_{2}}\right)\left(\beta+\delta_{1}+\frac{d_{1}(1-k) b_{2}}{a_{2}}\right)-\alpha \beta>0,
$$

then $A_{2}\left(0,0, \frac{b_{2}}{a_{2}}\right)$ is globally attractive, that is,

$$
\lim _{t \rightarrow+\infty} x_{i}(t)=0, \quad i=1,2, \quad \lim _{t \rightarrow+\infty} y(t)=\frac{b_{2}}{a_{2}} .
$$

Proof For a small enough positive constant $\varepsilon$, it follows from (3.1) that

$$
\left(\delta_{2}+d_{2}(1-k)\left(\frac{b_{2}}{a_{2}}+\varepsilon\right)\right)\left(\beta+\delta_{1}+d_{1}(1-k)\left(\frac{b_{2}}{a_{2}}+\varepsilon\right)\right)-\alpha \beta>0 .
$$

Now let us consider the equation

$$
\frac{d y}{d t}=y\left(b_{2}-a_{2} y\right)
$$

From Theorem 2.1 of [37] we know that the unique positive equilibrium $y^{*}=\frac{b_{2}}{a_{2}}$ is globally stable, that is,

$$
\lim _{t \rightarrow+\infty} y(t)=\frac{b_{2}}{a_{2}}
$$

Hence, for above $\varepsilon>0$, there exists $T>0$ such that

$$
y(t)<\frac{b_{2}}{a_{2}}+\varepsilon \quad \text { for all } t \geq T .
$$

Inequality (3.5), together with system (1.1), shows that, for $t>T$,

$$
\begin{aligned}
& \frac{d x_{1}}{d t} \leq \alpha x_{2}-\beta x_{1}-\delta_{1} x_{1}-d_{1}(1-k) x_{1}\left(\frac{b_{2}}{a_{2}}+\varepsilon\right), \\
& \frac{d x_{2}}{d t} \leq \beta x_{1}-\delta_{2} x_{2}-\gamma x_{2}^{2}-d_{2}(1-k) x_{2}\left(\frac{b_{2}}{a_{2}}+\varepsilon\right) .
\end{aligned}
$$


Now let us consider the system

$$
\begin{aligned}
& \frac{d u_{1}}{d t}=\alpha u_{2}-\beta u_{1}-\delta_{1} u_{1}-d_{1}(1-k) u_{1}\left(\frac{b_{2}}{a_{2}}+\varepsilon\right), \\
& \frac{d u_{2}}{d t}=\beta u_{1}-\delta_{2} u_{2}-\gamma u_{2}^{2}-d_{2}(1-k) u_{2}\left(\frac{b_{2}}{a_{2}}+\varepsilon\right) .
\end{aligned}
$$

It admits a boundary equilibrium $O(0,0)$. Now we show that, under assumption (3.1), $O(0,0)$ is globally asymptotically stable. We prove this by constructing some suitable Lyapunov function. Let us define the Lyapunov function

$$
V_{1}\left(u_{1}, u_{2}\right)=\frac{\beta}{\beta+\delta_{1}+d_{1}(1-k)\left(\frac{b_{2}}{a_{2}}+\varepsilon\right)} u_{1}+u_{2} .
$$

We can easily see that the function $V_{1}$ is zero at the boundary equilibrium $O(0,0)$ and is positive for all other positive values of $u_{1}$ and $u_{2}$. The time derivative of $V_{1}$ along the trajectories of (3.7) is

$$
\begin{aligned}
D^{+} V_{1}(t)= & \frac{\beta}{\beta+\delta_{1}+d_{1}(1-k)\left(\frac{b_{2}}{a_{2}}+\varepsilon\right)} \\
& \times\left(\alpha u_{2}-\beta u_{1}-\delta_{1} u_{1}-d_{1}(1-k) u_{1}\left(\frac{b_{2}}{a_{2}}+\varepsilon\right)\right) \\
& +\beta u_{1}-\delta_{2} u_{2}-\gamma u_{2}^{2}-d_{2}(1-k) u_{2}\left(\frac{b_{2}}{a_{2}}+\varepsilon\right) \\
= & \Upsilon x_{2}-\gamma x_{2}^{2},
\end{aligned}
$$

where

$$
\Upsilon=\frac{\alpha \beta}{\beta+\delta_{1}+d_{1}(1-k)\left(\frac{b_{2}}{a_{2}}+\varepsilon\right)}-\delta_{2}-d_{2}(1-k)\left(\frac{b_{2}}{a_{2}}+\varepsilon\right) .
$$

From (3.2) we have $\Upsilon<0$. It then follows from (3.1) and (3.9) that $D^{+} V_{1}(t)<0$ strictly for all $u_{1}, u_{2}>0$ except the boundary equilibrium $O(0,0)$, where $D^{+} V_{1}(t)=0$. Thus, $V_{1}\left(u_{1}, u_{2}\right)$ satisfies Lyapunov's asymptotic stability theorem, and the boundary equilibrium $O(0,0)$ of system (3.7) is globally asymptotically stable, that is, if $\left(u_{1}(t), u_{2}(t)\right)$ is any positive solution of system (3.7), then

$$
\lim _{t \rightarrow+\infty} u_{1}(t)=0, \quad \lim _{t \rightarrow+\infty} u_{2}(t)=0
$$

Let $\left(x_{1}(t), x_{2}(t), y(t)\right)$ be any positive solution of system (1.1) with initial condition $\left(x_{1}(0), x_{2}(0), y(0)=\left(x_{10}, x_{20}, y_{0}\right)\right.$, and let $\left(u_{1}(t), u_{2}(t)\right)$ be the positive solution of system (3.7) with initial condition $\left(u_{1}(0), u_{2}(0)\right)=\left(x_{10}, x_{20}\right)$. It then follows from the differential inequality theory that

$$
x_{i}(t) \leq u_{i}(t) \quad \text { for all } t \geq 0 \text {. }
$$


The positivity of the solution of system (1.1), together with (3.10) and (3.11), leads to

$$
0 \leq \liminf _{t \rightarrow+\infty} x_{i}(t) \leq \limsup _{t \rightarrow+\infty} x_{i}(t) \leq \lim _{t \rightarrow+\infty} u_{i}(t)=0, \quad i=1,2 .
$$

Hence

$$
\lim _{t \rightarrow+\infty} x_{i}(t)=0, \quad i=1,2 .
$$

Relation (3.4), together with (3.12), ends the proof of Theorem 3.1.

Remark 3.1 Under the assumption $\alpha \beta<\delta_{2}\left(\beta+\delta_{1}\right)$, it follows from Lemma 2.1 that the first species will be driven to extinction. In this case, for all $0<k<1$, inequality (3.1) holds, and it follows from Theorem 3.1 that $A_{2}\left(0,0, \frac{b_{2}}{a_{2}}\right)$ is globally attractive, which means that the first species is still driven to extinction.

Remark 3.2 Under the assumption $\alpha \beta>\delta_{2}\left(\beta+\delta_{1}\right)$, it follows from Lemma 2.1 that the first species is globally asymptotically stable; however, if

$$
k<1-\left(\frac{\alpha \beta}{\beta+\delta_{1}}-\delta_{2}\right) \frac{a_{2}}{b_{2} d_{2}},
$$

then inequality (3.1) holds, and it follows from Theorem 3.1 that $A_{2}\left(0,0, \frac{b_{2}}{a_{2}}\right)$ is globally attractive, which means that the first species will be driven to extinction, that is, if the cover for the first species is not large enough, then with the influence of the second species, the first species will be driven to extinction.

Remark 3.3 At first sight, system (1.1) is not complicate, and we may conjecture that it is easy to investigate the stability of the equilibrium by constructing a suitable Lyapunov function as that of An and Lei [36]; however, this is impossible, since the term $-d_{1}(1-k) x_{1} y$ in the first equation of system (1.1) cannot be dealt with directly. Here, by combining the differential inequality theory and the Lyapunov function we give a strict proof of Theorem 3.1. Such a method possibly could be applied to other situations.

Theorem 3.2 If

$$
\alpha \beta-\left(\delta_{2}+\frac{d_{2}(1-k) b_{2}}{a_{2}}\right)\left(\beta+\delta_{1}+\frac{d_{1}(1-k) b_{2}}{a_{2}}\right)>0,
$$

then $A_{4}\left(x_{1}^{* *}, x_{2}^{* *}, y^{* *}\right)$ is globally attractive.

Proof By (3.14) there exists an small enough positive constant $\varepsilon_{1}>0$ (without loss of generality, we may assume that $\varepsilon_{1}<\frac{b_{2}}{2 a_{2}}$ ) such that

$$
\alpha \beta-\left(\delta_{2}+d_{2}(1-k)\left(\frac{b_{2}}{a_{2}}+\varepsilon_{1}\right)\right)\left(\beta+\delta_{1}+d_{1}(1-k)\left(\frac{b_{2}}{a_{2}}+\varepsilon_{1}\right)\right)>0
$$

and

$$
\alpha \beta-\left(\delta_{2}+d_{2}(1-k)\left(\frac{b_{2}}{a_{2}}-\varepsilon_{1}\right)\right)\left(\beta+\delta_{1}+d_{1}(1-k)\left(\frac{b_{2}}{a_{2}}-\varepsilon_{1}\right)\right)>0 .
$$


Now let us consider the equation

$$
\frac{d y}{d t}=y\left(b_{2}-a_{2} y\right) \text {. }
$$

From Theorem 2.1 of [37] we know that the unique positive equilibrium $y^{* *}=\frac{b_{2}}{a_{2}}$ is globally stable, that is,

$$
\lim _{t \rightarrow+\infty} y(t)=\frac{b_{2}}{a_{2}} .
$$

Hence, for above $\varepsilon_{1}>0$, there exists $T_{1}>0$ such that

$$
\frac{b_{2}}{a_{2}}-\varepsilon_{1}<y(t)<\frac{b_{2}}{a_{2}}+\varepsilon_{1} \quad \text { for all } t \geq T_{1} .
$$

The right-hand side of (3.19), together with system (1.1), shows that, for $t>T_{1}$,

$$
\begin{aligned}
& \frac{d x_{1}}{d t} \leq \alpha x_{2}-\beta x_{1}-\delta_{1} x_{1}-d_{1}(1-k) x_{1}\left(\frac{b_{2}}{a_{2}}+\varepsilon_{1}\right), \\
& \frac{d x_{2}}{d t} \leq \beta x_{1}-\delta_{2} x_{2}-\gamma x_{2}^{2}-d_{2}(1-k) x_{2}\left(\frac{b_{2}}{a_{2}}+\varepsilon_{1}\right) .
\end{aligned}
$$

Now let us consider the system

$$
\begin{aligned}
& \frac{d u_{1}}{d t}=\alpha u_{2}-\beta u_{1}-\delta_{1} u_{1}-d_{1}(1-k) u_{1}\left(\frac{b_{2}}{a_{2}}+\varepsilon_{1}\right), \\
& \frac{d u_{2}}{d t}=\beta u_{1}-\delta_{2} u_{2}-\gamma u_{2}^{2}-d_{2}(1-k) u_{2}\left(\frac{b_{2}}{a_{2}}+\varepsilon_{1}\right) .
\end{aligned}
$$

Since inequality (3.15) holds, system (3.21) admits a unique positive equilibrium $M\left(u_{1}^{* *}\right.$, $\left.u_{2}^{* *}\right)$, where

$$
\begin{aligned}
& u_{1}^{* *}=\frac{\alpha u_{2}^{* *}}{\beta+\delta_{1}+d_{1}(1-k)\left(\frac{b_{2}}{a_{2}}+\varepsilon_{1}\right)}, \\
& u_{2}^{* *}=\frac{\alpha \beta-\left(\delta_{2}+d_{2}(1-k)\left(\frac{b_{2}}{a_{2}}+\varepsilon_{1}\right)\right)\left(\beta+\delta_{1}+d_{1}(1-k)\left(\frac{b_{2}}{a_{2}}+\varepsilon_{1}\right)\right)}{\left(\beta+\delta_{1}+d_{1}(1-k)\left(\frac{b_{2}}{a_{2}}+\varepsilon_{1}\right)\right) \gamma} .
\end{aligned}
$$

Obviously, $u_{1}^{* *}$ and $u_{2}^{* *}$ satisfy the equations

$$
\begin{aligned}
& \alpha u_{2}^{* *}-\beta u_{1}^{* *}-\delta_{1} u_{1}^{* *}-d_{1}(1-k) u_{1}^{* *}\left(\frac{b_{2}}{a_{2}}+\varepsilon_{1}\right)=0, \\
& \beta u_{1}^{* *}-\delta_{2} u_{2}^{* *}-\gamma\left(u_{2}^{* *}\right)^{2}-d_{2}(1-k) u_{2}^{* *}\left(\frac{b_{2}}{a_{2}}+\varepsilon_{1}\right)=0 .
\end{aligned}
$$

Now we show that $M\left(u_{1}^{* *}, u_{2}^{* *}\right)$ is globally asymptotically stable. We will prove this assertion by constructing some suitable Lyapunov function. Let us define the Lyapunov function

$$
V_{2}\left(u_{1}, u_{2}\right)=k_{1}\left(u_{1}-u_{1}^{* *}-u_{1}^{* *} \ln \frac{u_{1}}{u_{1}^{* *}}\right)+k_{2}\left(u_{2}-u_{2}^{* *}-u_{2}^{* *} \ln \frac{u_{2}}{u_{2}^{* *}}\right),
$$

where $k_{1}, k_{2}$ are some positive constants to be determined later. 
We can easily see that the function $V_{2}$ is zero at the equilibrium $M\left(u_{1}^{* *}, u_{2}^{* *}\right)$ and is positive for all other positive values of $u_{1}$ and $u_{2}$. The time derivative of $V_{2}$ along the trajectories of (3.21) is

$$
\begin{aligned}
D^{+} & V_{2}(t) \\
= & k_{1} \frac{u_{1}-u_{1}^{* *}}{u_{1}} \dot{u}_{1}+k_{2} \frac{u_{2}-u_{2}^{* *}}{u_{2}} \dot{u}_{2} \\
= & k_{1} \frac{u_{1}-u_{1}^{* *}}{u_{1}}\left(\alpha u_{2}-\left(\beta+\delta_{1}+d_{1}(1-k)\left(\frac{b_{2}}{a_{2}}+\varepsilon_{1}\right)\right) u_{1}\right) \\
& +k_{2} \frac{u_{2}-u_{2}^{* *}}{u_{2}}\left(\beta u_{1}-\delta_{2} u_{2}-\gamma u_{2}^{2}-d_{2}(1-k)\left(\frac{b_{2}}{a_{2}}+\varepsilon_{1}\right) u_{2}\right) .
\end{aligned}
$$

Note that from the relationship of $u_{1}^{* *}$ and $u_{2}^{* *}$ (see (3.22) for more detail) we have

$$
\begin{gathered}
\alpha u_{2}-\left(\beta+\delta_{1}+d_{1}(1-k)\left(\frac{b_{2}}{a_{2}}+\varepsilon_{1}\right)\right) u_{1} \\
=\frac{\alpha}{u_{1}^{* *}}\left(u_{2} u_{1}^{* *}-u_{1} u_{2}^{* *}\right)+\alpha u_{1} \frac{u_{2}^{* *}}{u_{1}^{* *}} \\
\quad-\left(\beta+\delta_{1}+d_{1}(1-k)\left(\frac{b_{2}}{a_{2}}+\varepsilon_{1}\right)\right) u_{1} \\
=\frac{\alpha}{u_{1}^{* *}}\left(u_{2} u_{1}^{* *}-u_{2} u_{1}+u_{2} u_{1}-u_{1} u_{2}^{* *}\right) \\
=\frac{\alpha}{u_{1}^{* *}}\left(-u_{2}\left(u_{1}-u_{1}^{* *}\right)+u_{1}\left(u_{2}-u_{2}^{* *}\right)\right) .
\end{gathered}
$$

Also, from the expression of $u_{2}^{* *}$, we have

$$
\begin{aligned}
\beta u_{1}- & \delta_{2} u_{2}-\gamma u_{2}^{2}-d_{2}(1-k)\left(\frac{b_{2}}{a_{2}}+\varepsilon_{1}\right) u_{2} \\
= & \frac{\beta}{u_{2}^{* *}}\left(u_{1} u_{2}^{* *}-u_{2} u_{1}^{* *}\right)+\beta u_{2} \frac{u_{1}^{* *}}{u_{2}^{* *}} \\
& \quad-\left(\delta_{2}+d_{2}(1-k)\left(\frac{b_{2}}{a_{2}}+\varepsilon_{1}\right)\right) u_{2}-\gamma u_{2}^{2} \\
= & \frac{\beta}{u_{2}^{* *}}\left(u_{1} u_{2}^{* *}-u_{1} u_{2}+u_{1} u_{2}-u_{2} u_{1}^{* *}\right)-\gamma u_{2}^{2} \\
& +\left(\frac{\alpha \beta}{\beta+\delta_{1}+d_{1}(1-k)\left(\frac{b_{2}}{a_{2}}+\varepsilon_{1}\right)}-\delta_{2}-d_{2}(1-k)\left(\frac{b_{2}}{a_{2}}+\varepsilon_{1}\right)\right) u_{2} \\
= & \frac{\beta}{u_{2}^{* *}}\left(u_{1}\left(u_{2}^{* *}-u_{2}\right)+u_{2}\left(u_{1}-u_{1}^{* *}\right)\right)+\gamma u_{2}^{* *} u_{2}-\gamma u_{2}^{2} .
\end{aligned}
$$

Applying (3.25) and (3.26) to (3.24) leads to

$$
\begin{aligned}
D^{+} V_{2}(t)= & k_{1} \frac{u_{1}-u_{1}^{* *}}{u_{1}} \frac{\alpha}{u_{1}^{* *}}\left(-u_{2}\left(u_{1}-u_{1}^{* *}\right)+u_{1}\left(u_{2}-u_{2}^{* *}\right)\right) \\
& +k_{2} \frac{u_{2}-u_{2}^{* *}}{u_{2}} \frac{\beta}{u_{2}^{* *}}\left(-u_{1}\left(u_{2}-u_{2}^{* *}\right)+u_{2}\left(u_{1}-u_{1}^{* *}\right)\right)
\end{aligned}
$$




$$
\begin{aligned}
& -k_{2} \gamma\left(u_{2}-u_{2}^{* *}\right)^{2} \\
= & -\frac{k_{1} \alpha u_{2}}{u_{1} u_{1}^{* *}}\left(u_{1}-u_{1}^{* *}\right)^{2}+\left(\frac{k_{1} \alpha}{u_{1}^{* *}}+\frac{k_{2} \beta}{u_{2}^{* *}}\right)\left(u_{1}-u_{1}^{* *}\right)\left(u_{2}-u_{2}^{* *}\right) \\
& -\frac{k_{2} \beta u_{1}}{u_{2} u_{2}^{* *}}\left(u_{2}-u_{2}^{* *}\right)^{2}-k_{2} \gamma\left(u_{2}-u_{2}^{* *}\right)^{2} .
\end{aligned}
$$

Now let us choose $k_{2}=1$ and $k_{1}=\frac{\beta u_{1}^{* *}}{u_{2}^{* * \alpha}}$. Then

$$
\begin{aligned}
D^{+} V_{2}(t)= & -\frac{\beta}{u_{2}^{* *}}\left[\sqrt{\frac{u_{2}}{u_{1}}}\left(u_{1}-u_{1}^{* *}\right)-\sqrt{\frac{u_{1}}{u_{2}}}\left(u_{2}-u_{2}^{* *}\right)\right]^{2} \\
& -\gamma\left(u_{2}-u_{2}^{* *}\right)^{2} .
\end{aligned}
$$

Hence $D^{+} V_{2}(t)<0$ strictly for all $u_{1}, u_{2}>0$ except the positive equilibrium $M\left(u_{1}^{* *}, u_{2}^{* *}\right)$, where $D^{+} V_{2}(t)=0$. Thus, $V_{2}(t)$ satisfies Lyapunov's asymptotic stability theorem, and the positive equilibrium $M\left(u_{1}^{* *}, u_{2}^{* *}\right)$ of system (3.21) is globally asymptotically stable, that is, if $\left(u_{1}(t), u_{2}(t)\right)$ is any positive solution of system (3.7), then

$$
\lim _{t \rightarrow+\infty} u_{1}(t)=u_{1}^{* *}, \quad \lim _{t \rightarrow+\infty} u_{2}(t)=u_{2}^{* *} .
$$

Let $\left(x_{1}(t), x_{2}(t), y(t)\right)$ be any positive solution of system (1.1) with initial condition $\left(x_{1}(0), x_{2}(0), y(0)=\left(x_{10}, x_{20}, y_{0}\right)\right.$, and let $\left(u_{1}(t), u_{2}(t)\right)$ be the positive solution of system (3.21) with initial condition $\left(u_{1}(0), u_{2}(0)\right)=\left(x_{10}, x_{20}\right)$. It then follows from the differential inequality theory that

$$
x_{i}(t) \leq u_{i}(t) \quad \text { for all } t \geq 0 .
$$

The positivity of the solution of system (1.1), together with (3.28) and (3.29), leads to

$$
\limsup _{t \rightarrow+\infty} x_{i}(t) \leq \lim _{t \rightarrow+\infty} u_{i}(t)=u_{i}^{* *}, \quad i=1,2 .
$$

On the other hand, the left-hand side of (3.19), together with system (1.1), shows that, for $t>T_{1}$,

$$
\begin{aligned}
& \frac{d x_{1}}{d t} \geq \alpha x_{2}-\beta x_{1}-\delta_{1} x_{1}-d_{1}(1-k) x_{1}\left(\frac{b_{2}}{a_{2}}-\varepsilon_{1}\right), \\
& \frac{d x_{2}}{d t} \geq \beta x_{1}-\delta_{2} x_{2}-\gamma x_{2}^{2}-d_{2}(1-k) x_{2}\left(\frac{b_{2}}{a_{2}}-\varepsilon_{1}\right) .
\end{aligned}
$$

Now let us consider the system

$$
\begin{aligned}
& \frac{d v_{1}}{d t}=\alpha v_{2}-\beta v_{1}-\delta_{1} v_{1}-d_{1}(1-k) v_{1}\left(\frac{b_{2}}{a_{2}}-\varepsilon_{1}\right), \\
& \frac{d v_{2}}{d t}=\beta v_{1}-\delta_{2} v_{2}-\gamma u_{2}^{2}-d_{2}(1-k) v_{2}\left(\frac{b_{2}}{a_{2}}-\varepsilon_{1}\right) .
\end{aligned}
$$


Since inequality (3.16) holds, system (3.32) admits a unique positive equilibrium $N\left(v_{1}^{* *}\right.$, $\left.v_{2}^{* *}\right)$, where

$$
\begin{aligned}
& v_{1}^{* *}=\frac{\alpha v_{2}^{* *}}{\beta+\delta_{1}+d_{1}(1-k)\left(\frac{b_{2}}{a_{2}}-\varepsilon_{1}\right)}, \\
& v_{2}^{* *}=\frac{\alpha \beta-\left(\delta_{2}+d_{2}(1-k)\left(\frac{b_{2}}{a_{2}}-\varepsilon_{1}\right)\right)\left(\beta+\delta_{1}+d_{1}(1-k)\left(\frac{b_{2}}{a_{2}}-\varepsilon_{1}\right)\right)}{\left(\beta+\delta_{1}+d_{1}(1-k)\left(\frac{b_{2}}{a_{2}}-\varepsilon_{1}\right)\right) \gamma} .
\end{aligned}
$$

Obviously, $v_{1}^{* *}$ and $v_{2}^{* *}$ satisfy the equations

$$
\begin{aligned}
& \alpha v_{2}^{* *}-\beta v_{1}^{* *}-\delta_{1} v_{1}^{* *}-d_{1}(1-k) v_{1}^{* *}\left(\frac{b_{2}}{a_{2}}-\varepsilon_{1}\right)=0, \\
& \beta v_{1}^{* *}-\delta_{2} v_{2}^{* *}-\gamma\left(v_{2}^{* *}\right)^{2}-d_{2}(1-k) v_{2}^{* *}\left(\frac{b_{2}}{a_{2}}-\varepsilon_{1}\right)=0 .
\end{aligned}
$$

Now we show that $N\left(v_{1}^{* *}, v_{2}^{* *}\right)$ is globally asymptotically stable. We will prove this assertion by constructing some suitable Lyapunov function. Let us define the Lyapunov function

$$
V_{3}\left(v_{1}, v_{2}\right)=l_{1}\left(v_{1}-v_{1}^{* *}-v_{1}^{* *} \ln \frac{v_{1}}{v_{1}^{* *}}\right)+l_{2}\left(v_{2}-v_{2}^{* *}-v_{2}^{* *} \ln \frac{v_{2}}{v_{2}^{* *}}\right)
$$

where $l_{1}, l_{2}$ are some positive constants to be determined later.

We easily see that the function $V_{3}$ is zero at the equilibrium $N\left(v_{1}^{* *}, v_{2}^{* *}\right)$ and is positive for all other positive values of $v_{1}$ and $v_{2}$. The time derivative of $V_{3}$ along the trajectories of (3.32) is

$$
\begin{aligned}
& D^{+} V_{3}(t) \\
& \quad=l_{1} \frac{v_{1}-v_{1}^{* *}}{v_{1}}\left(\alpha v_{2}-\left(\beta+\delta_{1}+d_{1}(1-k)\left(\frac{b_{2}}{a_{2}}-\varepsilon_{1}\right)\right) v_{1}\right) \\
& \quad+l_{2} \frac{v_{2}-v_{2}^{* *}}{v_{2}}\left(\beta v_{1}-\delta_{2} v_{2}-\gamma v_{2}^{2}-d_{2}(1-k)\left(\frac{b_{2}}{a_{2}}-\varepsilon_{1}\right) v_{2}\right) .
\end{aligned}
$$

Note that from the relationship of $v_{1}^{* *}$ and $v_{2}^{* *}$ (see (3.34) for more detail) we have

$$
\begin{gathered}
\alpha v_{2}-\left(\beta+\delta_{1}+d_{1}(1-k)\left(\frac{b_{2}}{a_{2}}+\varepsilon_{1}\right)\right) v_{1} \\
=\frac{\alpha}{v_{1}^{* *}}\left(-v_{2}\left(v_{1}-v_{1}^{* *}\right)+v_{1}\left(v_{2}-v_{2}^{* *}\right)\right) .
\end{gathered}
$$

Also, from the expression of $v_{2}^{* *}$ we have

$$
\begin{aligned}
\beta & v_{1}-\delta_{2} v_{2}-\gamma v_{2}^{2}-d_{2}(1-k)\left(\frac{b_{2}}{a_{2}}-\varepsilon_{1}\right) v_{2} \\
= & \frac{\beta}{v_{2}^{* *}}\left(v_{1}\left(v_{2}^{* *}-v_{2}\right)+v_{2}\left(v_{1}-v_{1}^{* *}\right)\right)+\gamma v_{2}^{* *} v_{2}-\gamma v_{2}^{2} .
\end{aligned}
$$


Applying (3.36) and (3.37) to (3.35) leads to

$$
\begin{aligned}
D^{+} V_{3}(t)= & -\frac{l_{1} \alpha v_{2}}{v_{1} v_{1}^{* *}}\left(v_{1}-v_{1}^{* *}\right)^{2}+\left(\frac{l_{1} \alpha}{v_{1}^{* *}}+\frac{l_{2} \beta}{v_{2}^{* *}}\right)\left(v_{1}-v_{1}^{* *}\right)\left(v_{2}-v_{2}^{* *}\right) \\
& -\frac{l_{2} \beta v_{1}}{v_{2} v_{2}^{* *}}\left(v_{2}-v_{2}^{* *}\right)^{2}-l_{2} \gamma\left(v_{2}-v_{2}^{* *}\right)^{2} .
\end{aligned}
$$

Now let us choose $l_{2}=1$ and $l_{1}=\frac{\beta v_{1}^{* *}}{v_{2}^{* * \alpha}}$. Then

$$
\begin{aligned}
D^{+} V_{3}(t)= & -\frac{\beta}{v_{2}^{* *}}\left[\sqrt{\frac{\nu_{2}}{v_{1}}}\left(v_{1}-v_{1}^{* *}\right)-\sqrt{\frac{\nu_{1}}{v_{2}}}\left(v_{2}-v_{2}^{* *}\right)\right]^{2} \\
& -\gamma\left(v_{2}-v_{2}^{* *}\right)^{2} .
\end{aligned}
$$

Hence $D^{+} V_{3}(t)<0$ strictly for all $v_{1}, v_{2}>0$ except the positive equilibrium $N\left(v_{1}^{* *}, v_{2}^{* *}\right)$, where $D^{+} V_{3}(t)=0$. Thus, $V_{3}(t)$ satisfies Lyapunov's asymptotic stability theorem, and the positive equilibrium $N\left(v_{1}^{* *}, v_{2}^{* *}\right)$ of system (3.32) is globally asymptotically stable, that is, if $\left(v_{1}(t), v_{2}(t)\right)$ is any positive solution of system (3.32), then

$$
\lim _{t \rightarrow+\infty} v_{1}(t)=v_{1}^{* *}, \quad \lim _{t \rightarrow+\infty} v_{2}(t)=v_{2}^{* *} .
$$

Let $\left(x_{1}(t), x_{2}(t), y(t)\right)$ be any positive solution of system (1.1) with initial condition $\left(x_{1}(0), x_{2}(0), y(0)=\left(x_{10}, x_{20}, y_{0}\right)\right.$, and let $\left(v_{1}(t), v_{2}(t)\right)$ be the positive solution of system (3.32) with initial condition $\left(v_{1}(0), v_{2}(0)\right)=\left(x_{10}, x_{20}\right)$. It then follows from the differential inequality theory that

$$
x_{i}(t) \geq v_{i}(t) \quad \text { for all } t \geq 0 .
$$

The positivity of the solution of system (1.1), together with (3.39) and (3.40), leads to

$$
\liminf _{t \rightarrow+\infty} x_{i}(t) \geq \lim _{t \rightarrow+\infty} v_{i}(t)=v_{i}^{* *}, \quad i=1,2
$$

Relation (3.30), together with (3.41), leads to

$$
v_{i}^{* *} \leq \liminf _{t \rightarrow+\infty} x_{i}(t) \leq \limsup _{t \rightarrow+\infty} x_{i}(t) \leq u_{i}^{* *}
$$

Noting that $\varepsilon_{1}$ is any small enough positive constant, from (2.8), (3.22), and (3.33) we have

$$
u_{i}^{* *} \rightarrow x_{i}^{* *}, \quad v_{i}^{* *} \rightarrow x_{i}^{* *} \quad \text { as } \varepsilon_{1} \rightarrow 0 .
$$

Letting $\varepsilon_{1} \rightarrow 0$ in (3.41), by (3.43) it immediately follows that

$$
\lim _{t \rightarrow+\infty} x_{i}(t)=x_{i}^{* *}, \quad i=1,2 .
$$

Relation (3.44), together with (3.17), ends the proof of Theorem 3.2. 
Remark 3.4 Condition (3.14) is necessary to ensure the existence of the positive equilibrium. Theorem 3.2 shows that if the positive equilibrium exists, then it is globally asymptotically stable, and hence it is impossible for the system to have the bifurcation phenomenon.

Remark 3.5 If $\alpha \beta>\delta_{2}\left(\beta+\delta_{1}\right)$, then for large enough $k$ ( $k$ is close to 1$)$ inequality (3.14) can hold, and from Lemma 2.1 we know that in this case, system (2.1) admits a unique positive equilibrium. In other words, if system (2.1) admits a unique positive equilibrium, then for the amensalism model, if the influence of the second species to the first species is limited, then the system still admits a unique globally asymptotically stable positive equilibrium.

\section{The influence of the partial cover}

From (2.8) we easily see that the final density of the immature and mature species are relevant to the partial cover, and hence one interesting issue is to find out a relationship between the final density of the species and the partial cover.

Note that from the second equality of (2.8) we have

$$
x_{2}^{* *}=\frac{1}{\gamma}\left(\frac{\alpha \beta}{\beta+\delta_{1}+\frac{d_{1}(1-k) b_{2}}{a_{2}}}-\left(\delta_{2}+\frac{d_{2}(1-k) b_{2}}{a_{2}}\right)\right) .
$$

Hence

$$
\frac{d x_{2}^{* *}(k)}{d k}=\frac{1}{\gamma}\left(\frac{\alpha \beta d_{1} b_{2}}{\left(\beta+\delta_{1}+\frac{d_{1}(1-k) b_{2}}{a_{2}}\right)^{2} a_{2}}+\frac{d_{2} b_{2}}{a_{2}}\right)>0 .
$$

Also, from the first equality of (2.8) and (4.2) we have

$$
\begin{aligned}
\frac{d x_{1}^{* *}(k)}{d k}= & \frac{\alpha d_{1} b_{2} x_{2}^{* *}}{\left(\beta+\delta_{1}+\frac{d_{1}(1-k) b_{2}}{a_{2}}\right)^{2} a_{2}} \\
& +\frac{\alpha}{\beta+\delta_{1}+\frac{d_{1}(1-k) b_{2}}{a_{2}}} \frac{d x_{2}^{* *}(k)}{d k} \\
> & 0,
\end{aligned}
$$

that is, increasing the partial cover will increase both the immature and mature first species density.

\section{Example}

Now let us consider the following example.

Example 5.1 Consider the two-species stage-structured amensalism model with a cover for the first species:

$$
\begin{aligned}
& \frac{d x_{1}}{d t}=4 x_{2}-x_{1}-x_{1}-(1-k) x_{1} y, \\
& \frac{d x_{2}}{d t}=x_{1}-x_{2}-x_{2}^{2}-(1-k) x_{2} y, \\
& \frac{d y}{d t}=y(1-y) .
\end{aligned}
$$




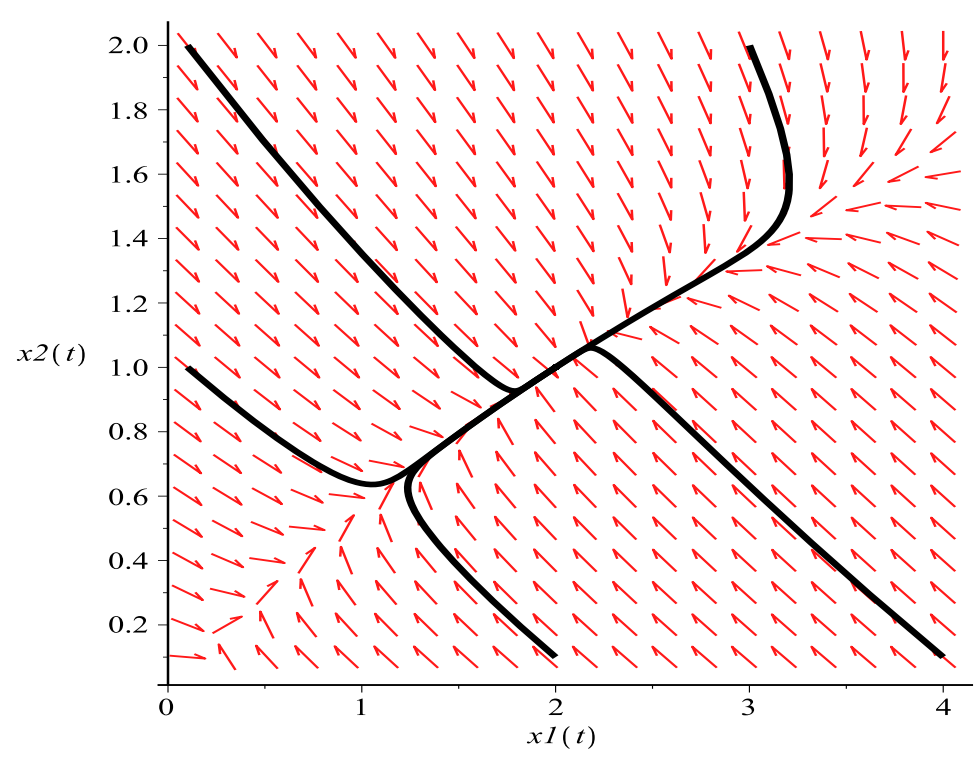

Figure 1 Dynamics behavior of system (5.2), the initial conditions $\left(x_{1}(0), x_{2}(0)\right)=(4,0.1),(3,2),(0.1,2),(0.1,1)$, and $(2,0.1)$, respectively

Here we choose $\alpha=4, \beta=\delta_{1}=\delta_{2}=\gamma=a_{2}=b_{2}=d_{1}=d_{2}=1$. Hence

$$
\alpha \beta=4>2=\delta_{2}\left(\beta+\delta_{1}\right) .
$$

Then, for the subsystem

$$
\begin{aligned}
& \frac{d x_{1}}{d t}=4 x_{2}-x_{1}-x_{1}, \\
& \frac{d x_{2}}{d t}=x_{1}-x_{2}-x_{2}^{2},
\end{aligned}
$$

it follows from Lemma 2.1 that the unique positive equilibrium $A(2,1)$ of system $(5.2)$ is globally asymptotically stable, that is, without the influence of the second species, the first species will be globally asymptotically stable (Fig. 1 supports this assertion).

System (5.1) has two equilibria $O(0,0,1)$ and $M\left(x_{1}^{*}(k), x_{2}^{*}(k), 1\right)$, where

$$
x_{1}^{*}(k)=-\frac{4\left(k^{2}-5 k+2\right)}{(k-3)^{2}}, \quad x_{2}^{*}(k)=\frac{k^{2}-5 k+2}{k-3} .
$$

By simple computation we know that, for $0<k<0.43845$, the boundary equilibrium $O(0,0,1)$ is globally attractive, and for $0.43845<k<1$, the unique positive equilibrium $M\left(x_{1}^{*}(k), x_{2}^{*}(k), 1\right)$ is globally attractive.

(1) Now let us choose $k=0.9$ in system $(5.1)$. Then $M(1.53288,0.80476,1)$ is globally attractive. Figures $2-4$ support this assertion.

(2) Now let us choose $k=0.2$ in system $(5.1)$. Then $M(0,0,1)$ is globally attractive. Figures $5-7$ support this assertion. 


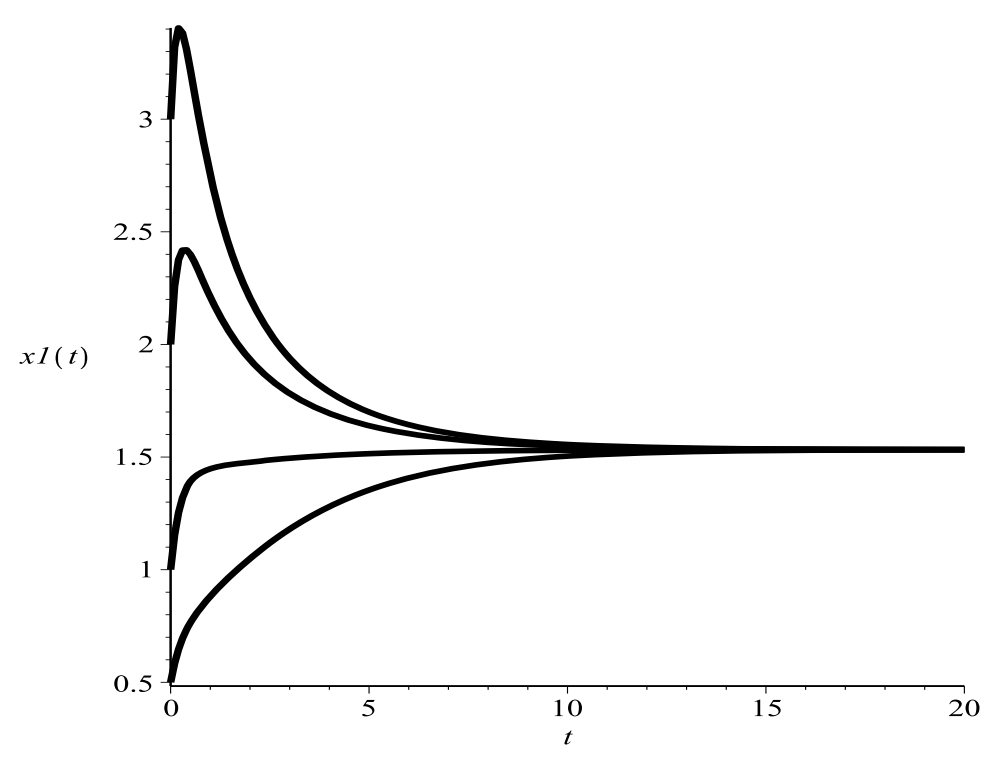

Figure 2 Dynamics behavior of the first component $x_{1}(t)$ of system (5.1); here we take $k=0.9$ and the initial conditions $\left(x_{1}(0), x_{2}(0), y(0)\right)=(0.5,0.5,0.5),(2,2,2),(1,1,1)$, and $(3,3,3)$, respectively

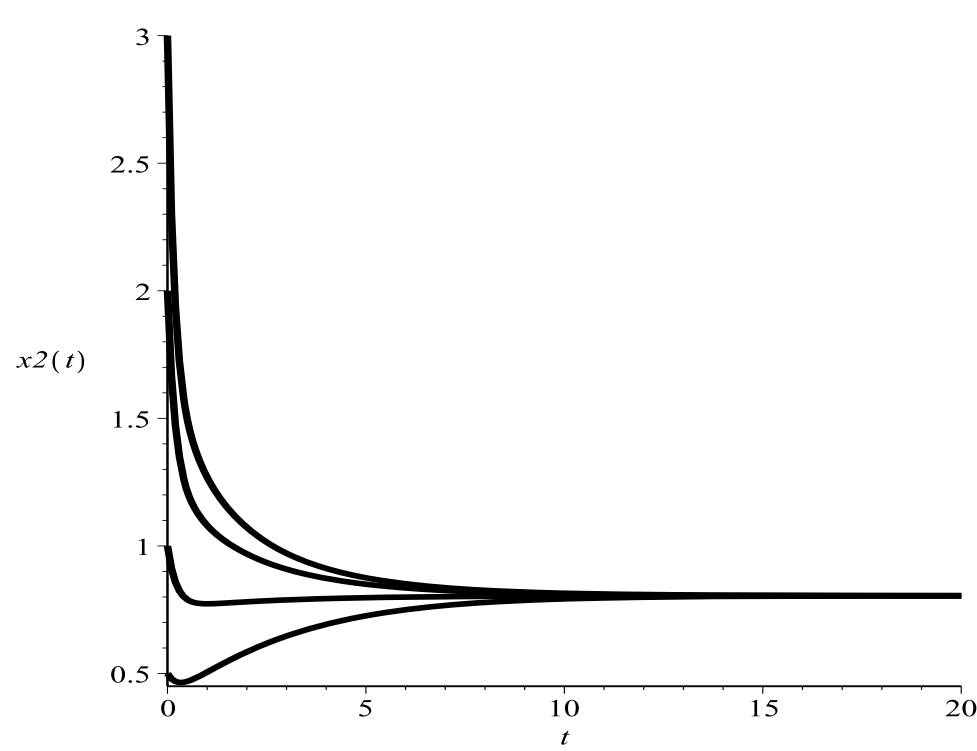

Figure 3 Dynamics behavior of the second component $x_{2}(t)$ of system (5.1); here we take $k=0.9$ and the initial conditions $\left(x_{1}(0), x_{2}(0), y(0)\right)=(0.5,0.5,0.5),(2,2,2),(1,1,1)$, and $(3,3,3)$, respectively

\section{Conclusion}

During the lase decade, many scholars [13-19] studied the dynamic behavior of the amensalism model; however, only recently, scholars $[14,16,18]$ studied the influence of the partial cover to the traditional two-species amensalism model. In this paper, for first time, we propose a two-species stage-structured amensalism model with a cover for the first species. 


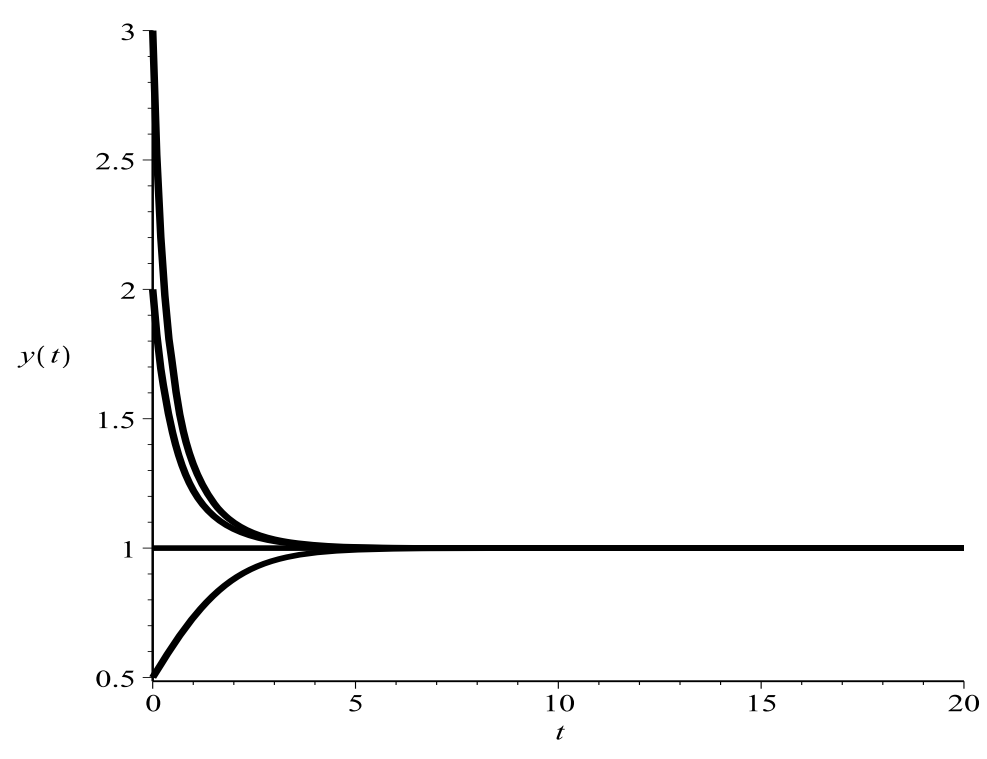

Figure 4 Dynamics behavior of the third component $y(t)$ of system (5.1); here we take $k=0.9$ and the initial conditions $\left(x_{1}(0), x_{2}(0), y(0)\right)=(0.5,0.5,0.5),(2,2,2),(1,1,1)$, and $(3,3,3)$, respectively

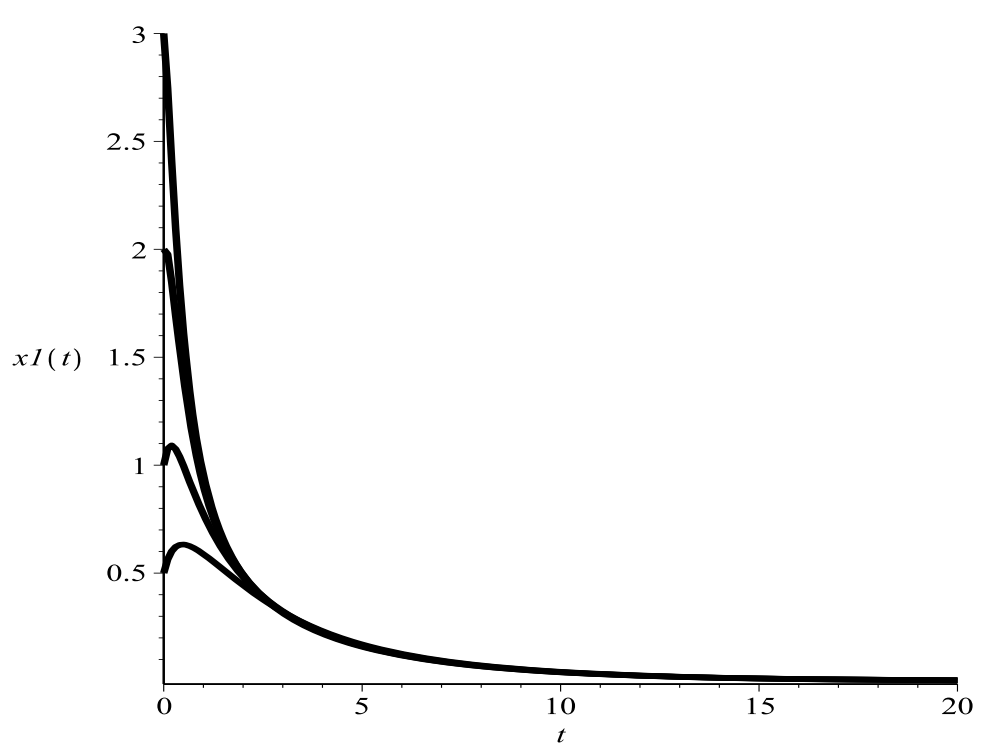

Figure 5 Dynamics behavior of the first component $x_{1}(t)$ of system (5.1); here we take $k=0.2$ and the initial conditions $\left(x_{1}(0), x_{2}(0), y(0)\right)=(0.5,0.5,0.5),(2,2,2),(1,1,1)$, and $(3,3,3)$, respectively

Though at first sight, the system seems very simple, note that the third equation of system (1.1) is independent of $x_{1}$ and $x_{2}$, and thus the Lyapunov method cannot be applied directly to investigate the stability property of system (1.1). By combining the differential inequality theory and the Lyapunov function method we are able to investigate the global stability property of the boundary and positive equilibrium. Theorem 3.2 shows that if the positive equilibrium exists, then it is globally attractive, and the final density of the first species is an increasing function of the partial cover. 


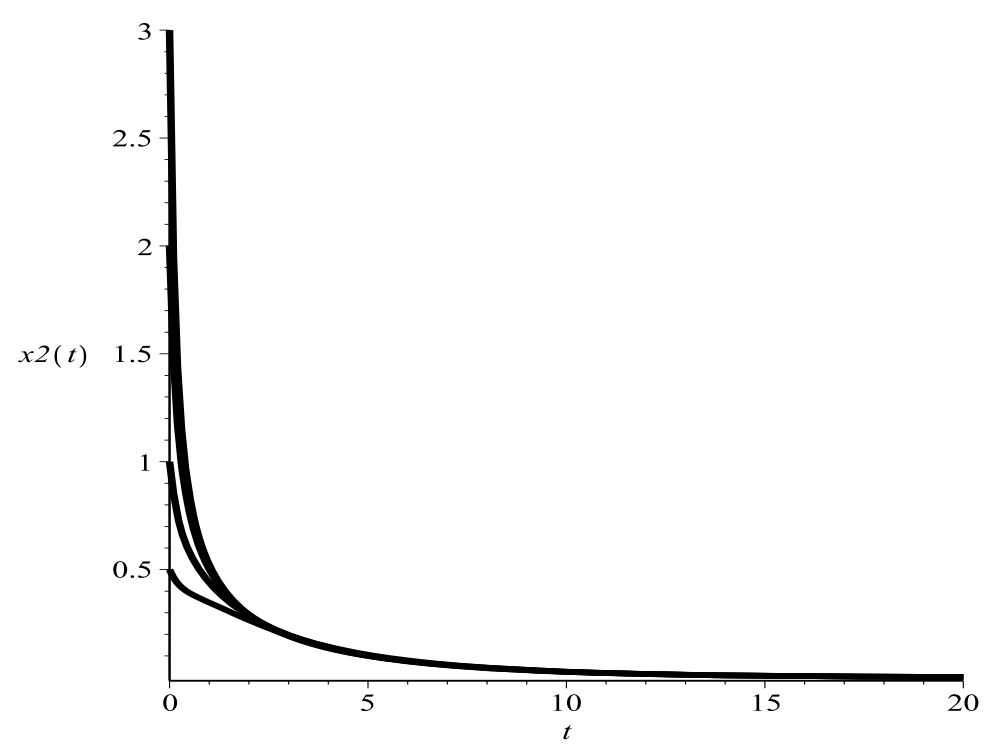

Figure 6 Dynamics behavior of the second component $x_{2}(t)$ of system (5.1); here we take $k=0.2$ and the initial conditions $\left(x_{1}(0), x_{2}(0), y(0)\right)=(0.5,0.5,0.5),(2,2,2),(1,1,1)$, and $(3,3,3)$, respectively

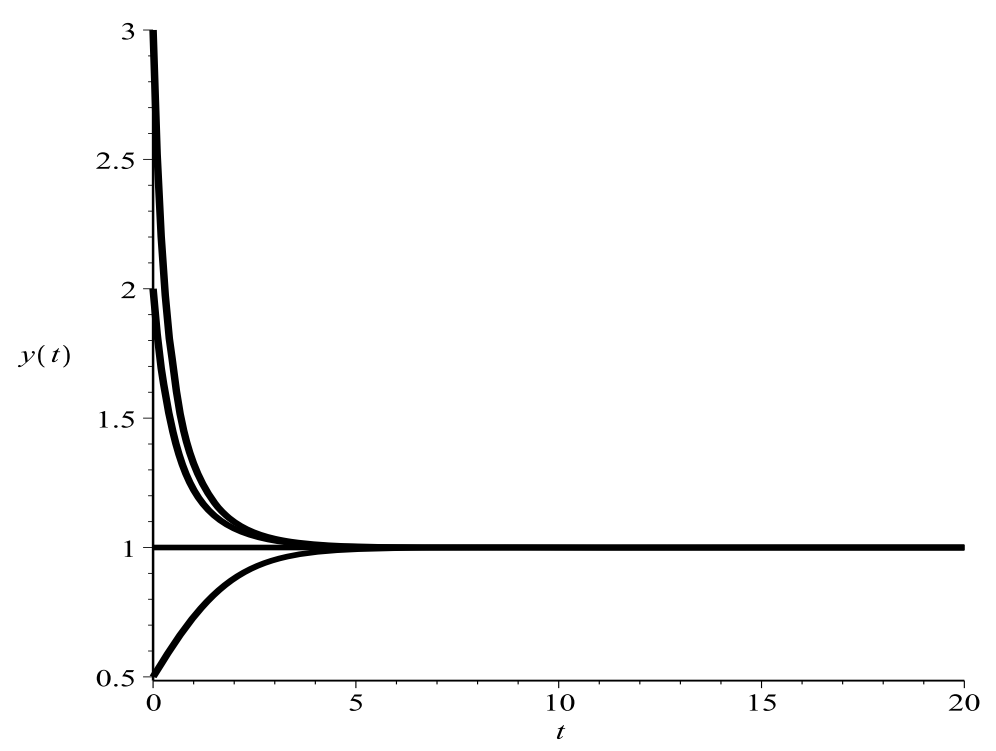

Figure 7 Dynamics behavior of the third component $y(t)$ of system (5.1); here we take $k=0.2$ and the initial conditions $\left(x_{1}(0), x_{2}(0), y(0)\right)=(0.5,0.5,0.5),(2,2,2),(1,1,1)$, and $(3,3,3)$, respectively

We mention here that the method used in this paper can be applied to investigate the stability property of the other ecosystem. We leave this for the future study.

\section{Acknowledgements}

I would like to thank Dr. Xuelin Xie for useful discussion during the period of writing this paper.

Funding

This work is supported by the National Natural Science Foundation of China under Grant (11601085) and the Natural Science Foundation of Fujian Province (2017J01400). 


\section{Competing interests}

The author declares that there is no conflict of interests.

\section{Authors' contributions}

All authors read and approved the final manuscript.

\section{Publisher's Note}

Springer Nature remains neutral with regard to jurisdictional claims in published maps and institutional affiliations.

Received: 23 May 2018 Accepted: 17 July 2018 Published online: 08 August 2018

\section{References}

1. Khajanchi, S., Banerjee, S.: Role of constant prey refuge on stage structure predator-prey model with ratio dependent functional response. Appl. Math. Comput. 314, 193-198 (2017)

2. Lin, Q.F.: Dynamic behaviors of a commensal symbiosis model with non-monotonic functional response and non-selective harvesting in a partial closure. Commun. Math. Biol. Neurosci. 2018, Article ID 4 (2018)

3. Wu, R.X., Li, L., Lin, Q.F.: A Holling type commensal symbiosis model involving Allee effect. Commun. Math. Biol. Neurosci. 2018, Article ID 6 (2018)

4. Wu, R.X., Li, L., Zhou, X.Y.: A commensal symbiosis model with Holling type functional response. J. Math. Comput. Sci. 16, 364-371 (2016)

5. Xie, X.D., Miao, Z.S., Xue, Y.L.: Positive periodic solution of a discrete Lotka-Volterra commensal symbiosis model. Commun. Math. Biol. Neurosci. 2015, Article ID 2 (2015)

6. Xue, Y.L., Xie, X.D., Chen, F.D., Han, R.Y.: Almost periodic solution of a discrete commensalism system. Discrete Dyn. Nat. Soc. 2015, Article ID 295483 (2015)

7. Chen, J.H., Wu, R.X.: A commensal symbiosis model with non-monotonic functional response. Commun. Math. Biol. Neurosci. 2017, Article ID 5 (2017)

8. Deng, H., Huang, X.Y.: The influence of partial closure for the populations to a harvesting Lotka-Volterra commensalism model. Commun. Math. Biol. Neurosci. 2018, Article ID 10 (2018)

9. Li, T.T., Lin, Q.X., Chen, J.H.: Positive periodic solution of a discrete commensal symbiosis model with Holling II functional response. Commun. Math. Biol. Neurosci. 2016, Article ID 22 (2016)

10. Zhu, Z.F., Chen, Q.L.: Mathematic analysis on commensalism Lotka-Volterra model of populations. J. Jixi Univ. 8(5) 100-101 (2008)

11. Lin, Q.F.: Allee effect increasing the final density of the species subject to Allee effect in a Lotka-Volterra commensal symbiosis model. Adv. Differ. Equ. 2018(1), 196 (2018)

12. Chen, B.G.: Dynamic behaviors of a commensal symbiosis model involving Allee effect and one party can not survive independently. Adv. Differ. Equ. 2018(1), 212 (2018)

13. Xiong, H.H., Wang, B.B., Zhang, H.L.: Stability analysis on the dynamic model of fish swarm amensalism. Adv. Appl. Math. 5(2), 255-261 (2016)

14. Wu, R.X., Zhao, L., Lin, Q.X.: Stability analysis of a two species amensalism model with Holling II functional response and a cover for the first species. J. Nonlinear Funct. Anal. 2016, Article ID 46 (2016)

15. Chen, B.: Dynamic behaviors of a non-selective harvesting Lotka-Volterra amensalism model incorporating partial closure for the populations. Adv. Differ. Equ. 2018(1), 111 (2018)

16. Sita Rambabu, B., Narayan, K.L., Bathul, S.: A mathematical study of two species amensalism model with a cover for the first species by homotopy analysis method. Adv. Appl. Sci. Res. 3(3), 1821-1826 (2012)

17. Lin, Q.X., Zhou, X.Y.: On the existence of positive periodic solution of a amensalism model with Holling II functional response. Commun. Math. Biol. Neurosci. 2017, Article ID 3 (2017)

18. Xie, X.D., Chen, F.D., He, M.X.: Dynamic behaviors of two species amensalism model with a cover for the first species J. Math. Comput. Sci. 16, 395-401 (2016)

19. Wu, R.: A two species amensalism model with non-monotonic functional response. Commun. Math. Biol. Neurosci. 2016, Article ID 19 (2016)

20. Chen, L., Wang, Y.: Dynamical analysis on prey refuge in a predator-prey model with square root functional response. J. Math. Comput. Sci. 18(2), 154-162 (2018)

21. Chen, L., Chen, F., Chen, L:: Qualitative analysis of a predator-prey model with Holling type II functional response incorporating a constant prey refuge. Nonlinear Anal., Real World Appl. 11(1), 246-252 (2010)

22. Wei, F., Fu, Q.: Globally asymptotic stability of a predator-prey model with stage structure incorporating prey refuge. Int. J. Biomath. 9(04), 1650058 (2016)

23. Chen, F., Ma, Z., Zhang, H.: Global asymptotical stability of the positive equilibrium of the Lotka-Volterra prey-predator model incorporating a constant number of prey refuges. Nonlinear Anal., Real World Appl. 13(6), 2790-2793 (2012)

24. Chen, F.D., Chen, W.L., Wu, Y.M., Ma, Z.Z.: Permanence of a stage-structured predator-prey system. Appl. Math. Comput. 219(17), 8856-8862 (2013)

25. Chen, F.D., Xie, X.D., Li, Z.: Partial survival and extinction of a delayed predator-prey model with stage structure. Appl. Math. Comput. 219(8), 4157-4162 (2012)

26. Chen, F.D., Wang, H.N., Lin, Y.H., Chen, W.L.: Global stability of a stage-structured predator-prey system. Appl. Math. Comput. 223, 45-53 (2013)

27. Lu, Y., Pawelek, K.A., Liu, S.: A stage-structured predator-prey model with predation over juvenile prey. Appl. Math Comput. 297, 115-130 (2017)

28. Ma, Z.H., Li, Z.Z., Wang, S.F., Li, T., Zhang, F.P.: Permanence of a predator-prey system with stage structure and time delay. Appl. Math. Comput. 201, 65-71 (2008)

29. Li, T.T., Chen, F.D., Chen, J.H., Lin, Q.X.: Stability of a mutualism model in plant-pollinator system with stage-structure and the Beddington-DeAngelis functional response. J. Nonlinear Funct. Anal. 2017, Article ID 50 (2017) 
30. Li, Z., Han, M., Chen, F.: Global stability of a predator-prey system with stage structure and mutual interference. Discrete Contin. Dyn. Syst., Ser. B 19(1), 173-187 (2014)

31. Chen, F.D., Xie, X.D., Chen, X.F.: Dynamic behaviors of a stage-structured cooperation model. Commun. Math. Biol. Neurosci. 2015, Article ID 4 (2015)

32. Lin, Y., Xie, X., Chen, F., et al.: Convergences of a stage-structured predator-prey model with modified Leslie-Gower and Holling-type II schemes. Adv. Differ. Equ. 2016(1), 181 (2016)

33. Pu, L.Q., Miao, Z.S., Han, R.Y.: Global stability of a stage-structured predator-prey model. Commun. Math. Biol. Neurosci. 2015, Article ID 5 (2015)

34. Han, R.Y., Yang, L.Y., Xue, Y.L.: Global attractivity of a single species stage-structured model with feedback control and infinite delay. Commun. Math. Biol. Neurosci. 2015, Article ID 6 (2015)

35. Wu, H.L., Chen, F.D.: Harvesting of a single-species system incorporating stage structure and toxicity. Discrete Dyn. Nat. Soc. 2009, Article ID 290123 (2009)

36. Xiao, A., Lei, C.Q.: Dynamic behaviors of a non-selective harvesting single species stage structure system incorporating partial closure for the populations. Adv. Differ. Equ. 2018(1), 245 (2018)

37. Chen, L.S.: Mathematical Models and Methods in Ecology. Science Press, Beijing (1988) (in Chinese)

\section{Submit your manuscript to a SpringerOpen ${ }^{\circ}$} journal and benefit from:

- Convenient online submission

$\checkmark$ Rigorous peer review

- Open access: articles freely available online

- High visibility within the field

- Retaining the copyright to your article

Submit your next manuscript at $\gg$ springeropen.com 